\title{
Morfología urbana y proceso de urbanización en Ecuador a través de la imagen satelital nocturna de la Tierra, 1992-2012
}

Verónica Mejía. Universitat Autònoma de Barcelona, Barcelona, España.

RESUMEN | El artículo analiza los procesos urbanos de los asentamientos del Ecuador por medio del uso de imágenes satelitales nocturnas, considerando la magnitud y la intensidad de la luminosidad, así como su evolución durante las últimas décadas. En una primera parte, se explica la metodología aplicada para determinar el umbral de luminosidad urbana usando las imágenes satelitales de la serie DMSP-OLs. Luego se analiza la intensidad de la luminosidad, así como la magnitud de las áreas con luminosidad urbana, y sus variaciones temporales. Los resultados obtenidos concuerdan con la hipótesis de que el proceso expansivo de baja densidad presente en las ciudades del Ecuador genera una rápida extensión de los usos urbanos, que pueden resultar ineficientes desde el punto de vista económico y poco sustentables ambientalmente. Por lo que a los aspectos metodológicos se refiere, el artículo muestra las potencialidades que pueden derivarse del uso de las fuentes y los procedimientos ensayados, relativamente innovadores en el contexto latinoamericano.

PALABRAS CLAVE | morfología urbana, expansión urbana, desigualdades regionales.

ABSTRACT | The article analyzes the urban processes of the main urban areas of Ecuador through the use of nocturnal satellite images, considering the magnitude and intensity of the luminosity, as well as its evolution during the last decades. In the first part, the methodology to determine the threshold of urban luminosity using the satellite images of the DMSP-OLS series is explained. Afterwards, the intensity of the luminosity is analyzed, along with the magnitude of the areas with urban luminosity, as well as their temporal variations. The results agree with the hypothesis that the expansive process of low-density development present in the cities of Ecuador, generates a rapid extension of the urban uses that can be inefficient from the economic point of view and unsustainable from the environmental perspective. Regarding the methodological aspects, the article shows the potential that can be derived from the sources and procedures tested, relatively innovative in the Latin American context.

KEYWORDS | urban morphology, urban sprawl, regional inequalities. 


\section{Introducción \\ El proceso de urbanización en Ecuador y la expansión de los usos urbanos del territorio}

En las últimas décadas del siglo xx y los primeros compases del xxI, la mayor parte del territorio del Ecuador ha conocido profundas mutaciones que han afectado tanto la estructura de los asentamientos humanos como los usos de suelo. Entre las principales expresiones de dichas transformaciones destacan por su importancia el incremento horizontal de las áreas urbanas, la invasión de tierras y el crecimiento demográfico. La urbanización se expande cada vez más como resultado de la intensificación de los usos periurbanos, de tal manera que la aparición de coágulos de usos urbanos dispersos por el territorio contribuye a la formación de extensas áreas donde la diferenciación entre el campo y la ciudad, tal como se ha entendido tradicionalmente, deviene casi imposible. En parte, esta situación, cuya sustentabilidad y eficiencia suscitan no pocas incógnitas, se debe a la carencia de herramientas, políticas y gestión de los suelos enfocadas a atender de manera efectiva la problemática social y física derivada de las transformaciones territoriales. Estas transformaciones no son, en modo alguno, privativas del Ecuador, sino comunes a la mayoría de los países de América Latina donde se han descrito fenómenos similares: la creciente concentración de población y actividades en unos o pocos centros urbanos principales, afección de ciudades intermedias y pequeñas e incremento de desequilibrios interregionales. Tal situación ha generado un proceso de urbanización acelerado y poco articulado. Las áreas urbanas en referencia devienen focos atractores de gran cantidad de población que se localiza en muchos casos en zonas de riesgo y en condiciones precarias, generando así áreas urbanizadas con densidades relativamente bajas. Estos problemas se ven agravados por fenómenos de inestabilidad política y estancamiento del desarrollo social, y se acentúan aún más por la escasa o inexistente capacidad administrativa (Roberts, 2015).

Como es sabido en términos generales, en América Latina el crecimiento demográfico fue relativamente lento hasta la mitad del siglo xx, cuando el sistema económico dependía primordialmente de la producción agrícola. Pero luego, con el cambio de las condiciones económicas y políticas, se produjo una brusca aceleración del crecimiento poblacional. Los desequilibrios territoriales se vieron fomentados en gran medida por reformas económicas que propiciaron la migración de la población rural, proceso que dio origen a asentamientos precarios en áreas urbanas carentes de servicios y sin las adecuadas condiciones de urbanización y vivienda (Davis, 2007).

Durante este siglo Xxi, algunos gobiernos han iniciado reformas para estabilizar la situación administrativa del país, reestructurar la economía y crear oportunidades para la inversión extranjera. Sin embargo, debido a las desigualdades regionales preexistentes, la brecha en el desarrollo se amplía cada vez más, quedándose las ciudades de menor orden rezagadas en su desarrollo. Asimismo, se evidencia una clara crisis de la política urbana o una ausencia de esta (Prada-Trigo, 2016; Roberts, 2015). En este contexto general, resulta innegable que cada país presenta especificidades propias, y el caso de Ecuador no es una excepción. En términos más o menos actuales, la administración pública ecuatoriana ha tratado de solventar la ausencia 
de políticas territoriales y urbanas, de tal modo que a partir de la Constitución de 2008 el ordenamiento territorial se volvió obligatorio para todos los niveles de gobierno. Esta obligatoriedad ha promovido algunos cambios materia de desarrollo y política territorial (Benabent \& Vivanco, 2017).

De acuerdo con la interpretación de Carrión (1994) sobre los procesos urbanos en Ecuador, para la comprensión de la especificidad del desarrollo urbano ecuatoriano se debe considerar, en primer lugar, las particularidades de la fundación de las ciudades en el país. Esta obedeció a lógicas coloniales y neocoloniales, que contribuyeron a configurar profundas desigualdades regionales. Desde esta perspectiva, seńala Carrión, pueden distinguirse dos grandes periodos en el proceso de urbanización en Ecuador. Denomina el primero, que se corresponde con la etapa de dominio colonial, como de conformación urbana. Las ciudades fundadas en la época de la Colonia respondían a requerimientos impuestos, y se localizaron como centros de control y desarrollo regional, generando así una estructura policéntrica. En un segundo periodo, iniciado a partir del final la guerra civil de 1895 y calificado por el autor como proceso de urbanización, se cristaliza la constitución del Estado ecuatoriano. En esta etapa se asientan las formas de producción e intercambio capitalista en la sociedad ecuatoriana sobre la base de un modelo agroexportador que permite la integración de la región de la Sierra y Costa, donde las plantaciones costeras sirven para atraer divisas por exportación, mientras que la hacienda serrana satisface el mercado interno. En términos de intercambio regional, podría afirmarse que la producción serrana era adquirida por la Costa, y la Sierra obtenía bienes manufacturados e importados a través de Guayaquil. Es así como el centro económico del país se desplaza de Quito a esta ciudad costera. Sin embargo, en 1972, con el boom petrolero, se consolida un proceso de urbanización bicefálico a escala nacional, ya que Quito se convierte en el centro de comercialización petrolera. De esta forma, Quito y Guayaquil se erigen como los principales polos estructurantes de los procesos de urbanización, atractores de población, capital y actividad productiva, lo que generó desigualdades y desarticulación con los demás centros urbanos. Dado este escenario, el avance de la urbanización en el resto del país dependió en buena medida de la estructura agraria regional (Carrión, 1994; Davis, 2007; PradaTrigo, 2016), situación que a su vez se relaciona con las fluctuaciones del comercio exterior, las cuales generaron épocas de dinamismo y otras de decadencia.

A lo largo de este proceso, los sistemas urbanos y las realidades locales han ido evolucionando, generando formas de urbanización diversas, que en la mayoría de los casos han resultado en expansiones urbanas donde los espacios construidos ocupan territorios cada vez más amplios y se extienden sobre el suelo rural y los espacios forestales. Como de forma reiterada ha explicado la literatura, la concreción de estos procesos ha sido posible solo gracias a la expansión de las infraestructuras de movilidad, el incremento de la motorización y la extensión de las redes de servicios (López, 2017). En este sentido, cabe destacar que en los últimos años se han realizado grandes inversiones en distintas infraestructuras vinculadas con la movilidad; entre estas, mejora de la red viaria, creación de nuevos aeropuertos, inversión en ferrocarriles y puertos, todo ello con el fin de mejorar el sistema productivo nacional (Prada-Trigo, 2016). 
En todo caso, el proceso evolutivo de buena parte de las ciudades y áreas urbanas ecuatorianas se corresponde, a grandes rasgos, con la tendencia general descrita por Nel.lo (1998) hace ya algunos años, caracterizada por la sucesión de distintas fases:

[...] del crecimiento de la ciudad "en mancha de aceite" (por simple agregación o ensanche sin solución de continuidad con el espacio construido preexistente) a la suburbanización (la aparición de periferias metropolitanas más o menos densas, a menudo sin solución de continuidad, como la ciudad central); de la suburbanización a la periurbanización (la integración en las dinámicas metropolitanas de los antiguos núcleos rurales); de la periurbanización a la rururbanización (la difusión de las dinámicas metropolitanas hasta los antiguos espacios rurales más alejados de los núcleos primigenios). (p. 39)

De esta forma, la expansión de la urbanización en Ecuador plantea con claridad los grandes temas que han sido abordados por la literatura sobre el proceso de urbanización: la expansión de las áreas urbanas, la integración del territorio y la dispersión de la urbanización (Indovina, 2007; Muñoz, 2007; Soja, 2008). En el presente artículo nos adentramos con especial atención en el estudio de la última de estas temáticas, entendida aquí como la expansión de los usos urbanos del suelo. Como se verá, la metodología seguida consiste esencialmente en la observación de la evolución de la luminosidad artificial nocturna, como indicador de la presencia de actividad antrópica. Se trata de un método nunca utilizado con anterioridad para el caso ecuatoriano. El trabajo contiene, además de la presente introducción, tres apartados: en el primero se detalla la metodología y las fuentes complementarias; en el segundo se exponen los resultados obtenidos y, finalmente, se discuten los hallazgos y conclusiones obtenidas.

\section{Metodología. La imagen satelital nocturna de la tierra como instrumento para conocimiento del proceso de urbanización}

\section{Las fuentes empleadas: potencialidades y limitaciones}

A partir de la segunda mitad del siglo xx, la medición y el estudio de los procesos de dispersión de la urbanización se han basado en muy buena medida en las fotografías aéreas y la imagen satelital diurna de la Tierra. Partiendo de estas fuentes, ha sido posible medir el alcance de las superficies artificializadas para usos urbanos y su progresiva expansión a lo largo del tiempo.

Sin embargo, en los últimos años se ha ido extendiendo el uso de la imagen satelital nocturna de la Tierra, la cual, como se verá, presenta algunas ventajas respecto a la imagen diurna. En efecto, en la última década, las imágenes satelitales nocturnas han sido empleadas para la realización de diversos estudios vinculados a temas muy diversos. Entre ellos, la localización y caracterización de conflictos armados (Li, Zhang, Huang, \& Li, 2015); la estimación del PIB, indicadores económicos y el nivel de desarrollo de los países (Elvidge, Baugh, Anderson, Sutton, \& Ghosh, 2012; Zhao, Currit, \& Samson, 2011; Elvidge et al., 2010); estudios demográficos y socioeconómicos (Levin \& Duke, 2012; Liang, Tanikawa, Matsuno, $\&$ Dong, 2014), e incluso temas relacionados con la salud, como las fluctuaciones 
estacionales de enfermedades (Bharti et al. 2011). Asimismo, se han realizado estudios con las imágenes nocturnas de la serie DMSP-OLs comparando la luminosidad con variables urbanas como población, producto interno bruto, área artificializada y consumo eléctrico (Ma, Zhou, Pei, Haynei, \& Fan, 2012; Kyba et al., 2017), sustentando así la relación existente entre la radiación lumínica generada por las ciudades y los procesos urbanos.

Para el estudio del proceso de urbanización, el uso de la imagen satelital nocturna presenta dos ventajas principales. En primer lugar, permite una aproximación más compleja a los usos de suelo. Así, mientras la delimitación del suelo artificializado comporta una visión de carácter binario de la urbanización (urbanizado/no urbanizado), la imagen nocturna de la Tierra permite observar no solo la extensión de los usos urbanos. sino también la intensidad de los mismos. En segundo lugar, la frecuencia y la cobertura permiten estudiar las variaciones temporales de las intensidades urbanas (Nel·lo, López, Martin, \& Checa, 2017).

En el presente trabajo se utiliza por primera vez la imagen nocturna de la Tierra como fuente principal del estudio que analiza la evolución de la urbanización en las principales ciudades del Ecuador, considerando tanto la magnitud como la intensidad de la luminosidad nocturna. Para ello se establecerá, en primer lugar, cuál es la relación entre los procesos de urbanización y la luminosidad nocturna, para estudiar, en segundo lugar, la evolución de esta.

La metodología empleada sigue la establecida por el Grupo de Investigación sobre Energía, Territorio y Sociedad, del Departamento de Geografía de la Universidad Autónoma de Barcelona, para el estudio del proceso de urbanización en Espańa (Nel.lo et al., 2017). La utilidad del método yace en el hecho de haber sido concebido para el estudio de la evolución de los usos urbanos del suelo en un periodo de veinte años, así como la evolución de la morfología urbana. El método empleado ofrece la posibilidad de establecer un umbral de luminosidad urbana, el cual permite realizar un análisis de la evolución de las superficies que han alcanzado dicho umbral en el periodo de tiempo considerado para el estudio.

Este método de análisis ha sido aplicado aquí, con algunas variantes, para el estudio de la expansión urbana en Ecuador entre 1992 y 2012, a fin de definir morfologías urbanas y procesos de urbanización en las principales ciudades del país. Así, como se verá, se ha establecido, en primer lugar, el umbral de luminosidad urbana para las principales ciudades del Ecuador. Luego se analiza la magnitud e intensidad de luminosidad producida por los asentamientos humanos, y se describe la evolución de la luminosidad en los años que cubre el estudio, considerando el crecimiento por periodos de cada cuatro años, es decir 1992, 1996, 2000, 2004, 2008 y 2012.

Como fuente principal se utilizaron las imágenes procedentes del National Geophysical Data Center, de la Nacional Oceanic and Atmospheric Administration (nOAA) del gobierno de los Estados Unidos de América. El Defense Meteorological Satellite Program-Operational Linescan System (DMSP-OLs) mantiene satélites que monitorean diversos aspectos del ambiente. Entre los productos elaborados se encuentran imágenes generadas por sensores satelitales que captan la luminosidad nocturna proveniente de la Tierra. A través de estas imágenes se logra observar la 
iluminación artificial que generan los usos antrópicos en el globo terrestre. Los sensores recolectan imágenes de una franja de $3.000 \mathrm{~km}$ sobre la superficie del globo, para lo cual realizan una cobertura global dos veces al día.

Las imágenes empleadas forman parte de la versión 4 de la serie de imágenes satelitales nocturnas multitemporales del DMSP-OLs, las cuales abarcan una temporalidad de 22 años, desde 1992 a 2013. Son archivos georreferenciados en formato raster que poseen una resolución con 30 segundos de arco, 1.000 x 1.000 m aproximadamente. Los pixeles de estas imágenes contienen valores de sensibilidad lumínica, corresponden a datos ponderados que se encuentran en un rango de 0 a 63 , siendo 63 el valor que representa la mayor luminosidad. Las imágenes empleadas son el resultado de un procesamiento de datos realizado por el NOAA. Están generadas con compuestos libres de nubes, se excluye en ellas el deslumbramiento solar y lunar; además, la serie de imágenes empleadas solo contiene datos de luces persistentes, descartando eventos efímeros, y con una limpieza del ruido de fondo.

$\mathrm{Al}$ realizar un análisis de los procesos urbanos presentes en el territorio ecuatoriano, se han tomado como base los principales centros poblados, los cuales corresponden a 28 asentamientos de jerarquía de Metrópolis, Nacional y Regional, según la tipología establecida en el Plan Nacional del Buen Vivir 2013-2017, ${ }^{1}$ y albergan al 78\% de la población urbana ecuatoriana. En su mayoría son capitales de provincia, y los demás se consideran asentamientos con roles importantes en el entorno en el que se emplazan, distribuidos por todo el territorio (figura 1). Para este estudio se ha excluido la región insular, Galápagos, ya que constituye en su totalidad un Parque Nacional en el cual se generan procesos de urbanización controlados y diferentes de los continentales.

Con el fin de contrastar las imágenes nocturnas con los datos ya existentes sobre la artificialización del suelo, se emplearon básicamente dos fuentes de información generales elaboradas por procesos de teledetección. La primera corresponde al Mapa de Cobertura y Uso de la Tierra del Ecuador Continental generado por el Ministerio del Ambiente (MAE) y el Ministerio de Agricultura, Ganadería, Acuacultura y Pesca (MAgap) para el periodo 2013-2014, ${ }^{2}$ el cual cubre todo el Ecuador Continental, es decir, $250.000 \mathrm{~km}^{2}$, con una escala 1:100.000. Esta fuente de información distingue, dentro de las áreas denominadas antrópicas, áreas pobladas e infraestructura. La segunda fuente de información considera la Cartografía Temática del Ecuador, generada por el proyecto del Sistema Nacional de Información de Tierras Rurales e Infraestructuras Tecnológicas (Sigtierras), proyecto emblemático del MAGar. ${ }^{3}$ Esta fuente presenta datos sobre la cobertura y uso de la tierra a una escala 1:25.000, con año de publicación 2015. El ámbito de estudio de este proyecto abarca $122.000 \mathrm{~km}^{2}$, superficie que cubre la mayor parte de la Amazonía ecuatoriana, parte de la Sierra y una pequeña área de la Costa, abarcando 14 de los 28 asentamientos del estudio. Esta fuente tiene un mayor nivel de detalle que la

1 Buen vivir. Plan nacional 2013-2017. Todo el mundo mejor (Quito: Secretaría Nacional de Planificación y Desarrollo, 2013), p. 359. En https:/observatorioplanificacion.cepal.org/es/ planes/plan-nacional-del-buen-vivir-2013-2017-de-ecuador

2 Secretaría Nacional de Planificación y Desarrollo, Sistema Nacional de Información. En http:// sni.gob.ec/mapa-cobertura-uso

3 Ministerio de Agricultura, Ganadería, Acuacultura y Pesca. En http://fliphtml5.com/wtae/wyjo 
anterior en la definición del territorio debido a la mayor resolución de los insumos empleados, que le permiten distinguir áreas pobladas, zonas edificadas, áreas periurbanas y en proceso de urbanización. Estos datos han sido facilitados por la Secretaría Nacional de Planificación y Desarrollo (Senplades)

Además de estas dos fuentes que emplean como herramienta base la teledetección, se ha utilizado, a efectos comparativos, una fuente distinta: el mapa de densidades generadas por el Gobierno Autónomo Descentralizado Municipal de Cuenca (GADMC), obtenido por un procesamiento de información territorial secundaria, que toma como base la dotación de servicios para la representación cartográfica de la población sobre el territorio. ${ }^{4}$

Cabe mencionar que para una segunda fase de la presente investigación se está trabajando sobre la nueva serie de imágenes satelitales Versión 1 virrs Day/Night Band Nighttime Lights, las cuales proporcionan datos sobre la radiación nocturna cuyos valores corresponden a niveles de radiación en nanoWatts $/\left(\mathrm{cm}^{2} / \mathrm{sr}\right) .^{5}$

\section{Premisa básica: Definición de umbral de luminosidad urbana}

Considerando que el objetivo del estudio es analizar el proceso de urbanización en el territorio, las superficies obtenidas a través de este método son consideradas un indicador del proceso de ocupación del suelo con usos urbanos. Siendo así, el umbral de luminosidad urbana es concebido como un valor normativo que permite comparar diversos periodos temporales, allí donde no se cuenta con mapas de coberturas de suelo. El umbral se define como el nivel de luminosidad que incluye un mayor porcentaje de suelo artificializado por usos urbanos, a la vez que un menor porcentaje de área iluminada no artificializada para estos fines.

Para determinar el umbral de luminosidad urbana se realiza un cruce de información entre la imagen satelital nocturna y diversas fuentes relativas a la extensión de la artificialización del suelo. Para este análisis se contempla circunferencias de radios de $25 \mathrm{~km}$ generados desde los centroides de los 28 asentamientos urbanos identificados. El radio de $25 \mathrm{~km}$ ha sido determinado por constituir una distancia que abarca los procesos urbanos vinculados a los principales centros poblados del Ecuador y evita que se generen demasiados solapamientos entre asentamientos que se encuentran muy próximos. Tomando este ámbito, también se descartan asentamientos urbanos menores donde no existe mayor actividad antrópica y que no generan suficiente luminosidad para ser considerados dentro de este análisis, como ocurre en gran parte de la Amazonía. La figura 1 muestra la imagen satelital

4 Véase I. Municipalidad de Cuenca / Universidad del Azuay, Formulación del Plan de Desarrollo y Ordenamiento Territorial del Cantón Cuenca. Tomo I: Diagnóstico Sectorial e Integrado (enerodiciembre 2011). En https://drive.google.com/file/d/1FCgwqlLRt7aWtVsu3e2k-lE_jZ9qaUKK/ view. Todos los Planes de Desarrollo y Ordenamiento Territorial están disponibles en http://sni. gob.ec/pdyot

5 Esta nueva serie de imágenes posee una mayor calidad y resolución, pasa la cuantificación radiométrica de 6 bits en las DMSP a 14 bits, y presenta una amplia gama de detección radiométrica. Además, la serie provee imágenes generadas por promedios mensuales y anuales correspondientes a una temporalidad de seis años, desde 2012 a 2017, lo que proporciona un amplio abanico de posibilidades de análisis. 
nocturna con sus distintas intensidades, donde se observa que las mayores intensidades coinciden con los centros poblados.

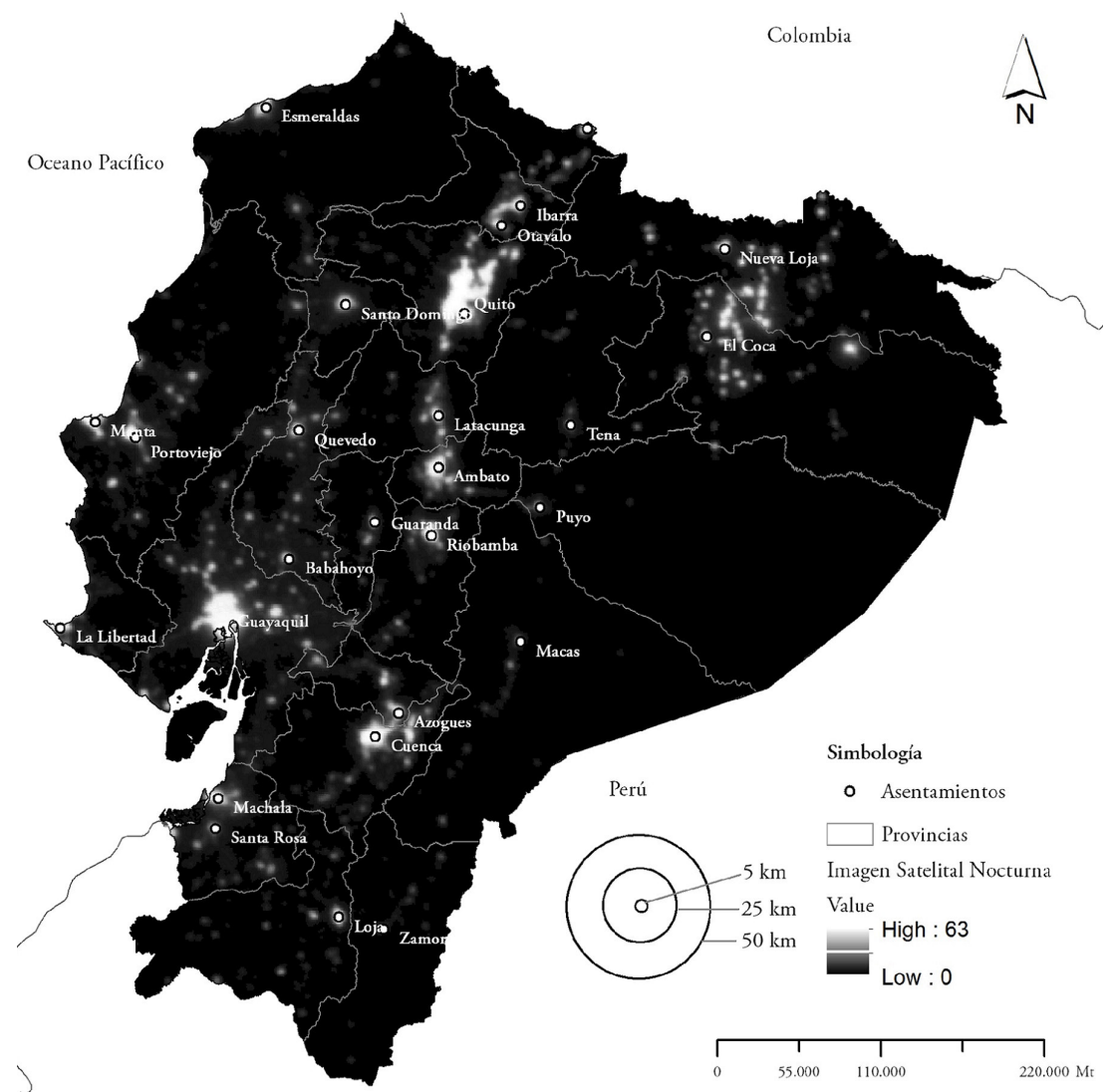

FIGURA I | Imagen satelital nocturna, 2013

FUENTE: ELABORACIÓN PROPIA CON BASE EN LA IMAGEN SATELITAL NOCTURNA, 2 OI 3 DMSP-OLS

Con el cruce realizado y definido el ámbito de análisis, se examinan los datos intersectados para determinar el valor del umbral. En la tabla 1 se presentan, a modo de ejemplo para la descripción de la metodología, los datos obtenidos con el cruce de información entre áreas urbanas definidas del MAE-MAGAP, por una parte, y la imagen satelital nocturna, por la otra. Iniciando desde el pixel de luz 63, que es el de mayor luminosidad, la superficie que ha alcanzado este nivel de luminosidad (Área Iluminada) irá aumentando según se disminuya la intensidad lumínica, lo cual conlleva un aumento de la superficie urbana incluida en la superficie iluminada (Área Intersectada). La columna que contiene el cociente generado por el Área Intersectada y Área Total muestra la relación entre el área urbana iluminada y el Área Total analizada, la cual incluye el área iluminada y el área urbana no intersectada. El valor máximo de esta columna permite identificar el umbral que incluye la mayor 
extensión de suelo urbano y, a la vez, una menor extensión de suelo no urbano. Así, en la tabla 1 se observa cómo este cociente va ascendiendo desde el pixel 63, hasta llegar a un valor máximo en el pixel 56. Es decir que, dentro del ámbito de las 28 áreas consideradas, el nivel de luminosidad de 56 pixeles es el que tiene una máxima correspondencia con las áreas urbanizadas. A partir de este nivel, los incrementos de superficie correspondientes a niveles de luminosidad inferiores incluyen un mayor porcentaje de suelo no artificializado para usos urbanos, que suelo artificializado. Es así como este nivel de máxima correspondencia es el que determina lo que se ha denominado umbral de luminosidad urbana.

\begin{tabular}{|c|c|c|c|c|c|c|c|c|}
\hline PIXEL & $\begin{array}{c}\text { ÁREA } \\
\text { URBANA } \\
\left(\mathbf{K M}^{2}\right)\end{array}$ & $\begin{array}{c}\text { ÁREA } \\
\text { ILUMINADA } \\
\left(\mathbf{K M}^{2}\right)\end{array}$ & $\begin{array}{c}\text { ÁREA } \\
\text { INTER- } \\
\text { SECTADA } \\
\left(\mathrm{KM}^{2}\right)\end{array}$ & $\begin{array}{c}\text { URBANA } \\
\text { NO INTER- } \\
\text { SECTADA } \\
\left(\mathrm{KM}^{2}\right)\end{array}$ & $\begin{array}{c}\text { LUZ NO } \\
\text { INTER- } \\
\text { SECTADA } \\
\left(\mathrm{KM}^{2}\right)\end{array}$ & $\begin{array}{c}\text { ÁREA } \\
\text { TOTAL } \\
\left(\mathrm{KM}^{2}\right)\end{array}$ & $\begin{array}{c}\text { INTER- } \\
\text { SECTADA } \\
\text { / ÁREA } \\
\text { TOTAL (\%) }\end{array}$ & $\begin{array}{c}\text { ÁREA } \\
\text { URBANA } \\
\text { CONSI- } \\
\text { DERADA } \\
(\%)\end{array}$ \\
\hline 63 & $1.550,1$ & 422,5 & 338,8 & $1.211,3$ & 83,7 & $1.633,7$ & $20,7 \%$ & $21,9 \%$ \\
\hline 62 & $1.550,1$ & 822 & 600,8 & 949,3 & 221,2 & $1.771,3$ & $33,9 \%$ & $38,8 \%$ \\
\hline 61 & $1.550,1$ & $1.064,1$ & 717,2 & 832,8 & 346,9 & 1.897 & $37,8 \%$ & $46,3 \%$ \\
\hline 60 & $1.550,1$ & $1.238,7$ & 796,8 & 753,2 & 441,8 & $1.991,9$ & $40,0 \%$ & $51,4 \%$ \\
\hline 59 & $1.550,1$ & 1.391 & 852,3 & 697,7 & 538,7 & $2.088,7$ & $40,8 \%$ & $55,0 \%$ \\
\hline 58 & $1.550,1$ & $1.520,1$ & 894,3 & 655,8 & 625,8 & $2.175,9$ & $41,1 \%$ & $57,7 \%$ \\
\hline 57 & $1.550,1$ & $1.634,5$ & 934,2 & 615,9 & 700,3 & $2.250,3$ & $41,5 \%$ & $60,3 \%$ \\
\hline 56 & $1.550,1$ & $1.768,4$ & 975 & 575,1 & 793,5 & $2.343,5$ & $41,6 \%$ & $62,9 \%$ \\
\hline 55 & $1.550,1$ & $1.890,8$ & $1.006,4$ & 543,6 & 884,4 & $2.434,4$ & $41,3 \%$ & $64,9 \%$ \\
\hline 54 & $1.550,1$ & $2.008,4$ & $1.039,5$ & 510,6 & 968,9 & 2.519 & $41,3 \%$ & $67,1 \%$ \\
\hline 53 & $1.550,1$ & 2.103 & 1.063 & 487,1 & 1.040 & $2.590,1$ & $41,0 \%$ & $68,6 \%$ \\
\hline 52 & $1.550,1$ & $2.195,9$ & $1.086,1$ & 464 & $1.109,8$ & $2.659,9$ & $40,8 \%$ & $70,1 \%$ \\
\hline 51 & $1.550,1$ & $2.302,3$ & 1.104 & 446,1 & $1.198,3$ & $2.748,4$ & $40,2 \%$ & $71,2 \%$ \\
\hline 50 & $1.550,1$ & $2.407,9$ & $1.126,2$ & 423,9 & $1.281,8$ & $2.831,8$ & $39,8 \%$ & $72,7 \%$ \\
\hline 49 & $1.550,1$ & 2.509 & $1.144,2$ & 405,9 & $1.364,8$ & $2.914,9$ & $39,3 \%$ & $73,8 \%$ \\
\hline 48 & $1.550,1$ & $2.608,6$ & $1.159,9$ & 390,2 & $1.448,7$ & $2.998,8$ & $38,7 \%$ & $74,8 \%$ \\
\hline 47 & $1.550,1$ & $2.707,3$ & $1.176,1$ & 374 & $1.531,2$ & $3.081,2$ & $38,2 \%$ & $75,9 \%$ \\
\hline 46 & $1.550,1$ & $2.810,1$ & $1.187,9$ & 362,1 & $1.622,2$ & $3.172,2$ & $37,4 \%$ & $76,6 \%$ \\
\hline 45 & $1.550,1$ & $2.913,4$ & $1.206,9$ & 343,1 & $1.706,5$ & $3.256,6$ & $37,1 \%$ & $77,9 \%$ \\
\hline 44 & $1.550,1$ & $3.011,2$ & $1.222,3$ & 327,8 & 1.789 & 3.339 & $36,6 \%$ & $78,9 \%$ \\
\hline 43 & $1.550,1$ & $3.126,1$ & $1.235,3$ & 314,7 & $1.890,8$ & $3.440,9$ & $35,9 \%$ & $79,7 \%$ \\
\hline 42 & $1.550,1$ & $3.248,1$ & $1.253,3$ & 296,8 & $1.994,8$ & $3.544,9$ & $35,4 \%$ & $80,9 \%$ \\
\hline 41 & $1.550,1$ & $3.347,1$ & $1.264,5$ & 285,6 & $2.082,6$ & $3.632,7$ & $34,8 \%$ & $81,6 \%$ \\
\hline
\end{tabular}

TABLA I | Cruce de niveles de luminosidad con áreas urbanas en el conjunto de 28 asentamientos en un ámbito $25 \mathrm{~km}$ de radio

FUENTE: ELABORACIÓN PROPIA CON BASE EN DATOS DEL MAE E IMÁGENES DMSP-OLS

A fin de comparar y validar los resultados obtenidos con los radios de $25 \mathrm{~km}$ alrededor de las principales áreas urbanas, se ha realizado un trabajo similar en que se incluyen diferentes ámbitos de estudio: el conjunto del área del Ecuador continental, y los espacios conformados por circunferencias de $50 \mathrm{~km}$, considerando así un territorio más amplio y otro de $5 \mathrm{~km}$ de radio que abarca los núcleos centrales de los asentamientos. De este modo se han obtenido los umbrales de luminosidad urbana que se derivarían en la consideración del conjunto del territorio nacional 
en el continente, desde una delimitación más amplia de los entornos urbanos hasta otra más restringida.

La tabla 2 muestra los resultados obtenidos, identificándose valores referentes al pixel de máxima correspondencia entre áreas intersectadas y Área Total para cada uno de los ámbitos considerados y las dos fuentes utilizadas. En este artículo se han omitido los cálculos, por temas de extensión. Como puede verse, el umbral de luminosidad urbana oscila, según los casos, entre los pixeles 50 y 56 . Aunque es evidente que los valores de máxima correspondencia obtenidos con la fuente de información de Sigtierras son menores, esto se debe a que con un nivel inferior de luminosidad se abarca más suelo, lo que está acorde con los datos de esta fuente, puesto que ella incluye mayor cantidad de suelo con usos urbanos, por la escala y el nivel de detalle que presenta.

En términos generales, puede afirmarse que mientras menor es el ámbito de estudio, existe una mayor correspondencia con el área urbana considerada. Esto significa que el umbral de luminosidad establecido con el radio de $5 \mathrm{~km}$ abarca un mayor porcentaje de suelo urbano, tanto si lo comparamos con el área iluminada como si lo hacemos con el total del área urbana establecida por las fuentes antes mencionadas. Por otro lado, al considerar los ámbitos de $25 \mathrm{~km}$, se estaría incluyendo suelos más vinculados con los procesos de urbanización próximos a los asentamientos analizados. En cambio, al considerar los ámbitos de $50 \mathrm{~km}$ de radio, se abarca un territorio bastante extenso, en el cual se incluyen procesos de urbanización menores que se desarrollan en áreas más alejadas de los principales centros; en este caso, sin embargo, la correspondencia con el Área Intersectada y el Área Total disminuye considerablemente. Finalmente, al considerar todo el territorio continental, se observa que los datos referidos al umbral de luminosidad urbana, los porcentajes de suelo urbano con respecto al porcentaje de área urbana considerada y el porcentaje de Área Intersectada con respecto al Área Total, son similares a los obtenidos en el ámbito de $50 \mathrm{~km}$. Ello permite concluir que la existencia de asentamientos menores que se encuentran fuera del ámbito de $50 \mathrm{~km}$ no afecta de manera significativa la relación entre las variables de luz y las áreas urbanas.

\begin{tabular}{|c|c|c|c|c|c|c|c|c|}
\hline \multirow{2}{*}{$\begin{array}{l}\text { FUENTE } \\
\text { ÁMBITO }\end{array}$} & \multicolumn{4}{|c|}{ MAE-MAGAP } & \multicolumn{4}{|c|}{ SIGTIERRAS } \\
\hline & $\begin{array}{l}\text { CONTI- } \\
\text { NENTE }\end{array}$ & $50 \mathrm{KM}$ & $25 \mathrm{KM}$ & $5 \mathrm{KM}$ & $\begin{array}{l}\text { CONTI- } \\
\text { NENTE }\end{array}$ & $50 \mathrm{KM}$ & $25 \mathrm{KM}$ & $5 \mathrm{KM}$ \\
\hline $\begin{array}{l}\text { Máxima } \\
\text { coincidencia }\end{array}$ & 54 & 54 & 56 & 52 & 50 & 50 & 50 & 52 \\
\hline $\begin{array}{l}\text { Área de estudio } \\
\left(\mathrm{km}^{2}\right)\end{array}$ & 248.744 & 129.954 & 43.898 & 2.152 & 122.275 & 56.272 & 21.576 & 1.086 \\
\hline $\begin{array}{l}\text { Área urbana } \\
\left(\mathrm{km}^{2}\right)\end{array}$ & 2.031 & 1.848 & 1.550 & 654 & 992,2 & 817 & 678 & 330,2 \\
\hline $\begin{array}{l}\text { Intersectada/ } \\
\text { Área total }\end{array}$ & $35 \%$ & $36 \%$ & $41 \%$ & $49 \%$ & $24 \%$ & $28 \%$ & $33 \%$ & $50 \%$ \\
\hline $\begin{array}{l}\% \text { área urbana } \\
\text { considerada }\end{array}$ & $52 \%$ & $57 \%$ & $62 \%$ & $81 \%$ & $34 \%$ & $42 \%$ & $50 \%$ & $72 \%$ \\
\hline
\end{tabular}

TABLA 2 Valores de máxima coincidencia entre áreas urbanas y niveles de

\section{luminosidad}

FUENTE: ELABORACIÓN PROPIA CON BASE EN DATOS DEL MAE E IMÁGENES DMSP-OLS 
También se ha querido explorar si el umbral de luminosidad varía según las áreas geográficas. A estos efectos se han agrupado los datos por regiones naturales -Costa, Sierra y Amazonía- tratando de identificar las posibles variaciones derivadas de las condiciones físicas, la evolución histórica y las condiciones socioeconómicas de cada ámbito. Según los datos que se presentan en la tabla 3, la Sierra posee un umbral de luminosidad urbana superior al del resto de regiones, lo que indicaría que las áreas urbanas de la Sierra emiten más luz, en términos medios, por superficie ocupada, y las áreas urbanas de la Amazonía emiten menos luz.

\begin{tabular}{|c|c|c|c|c|c|c|c|c|c|c|}
\hline \multirow[b]{2}{*}{ 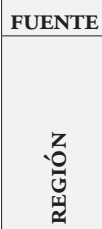 } & \multicolumn{6}{|c|}{ MAE - MAGAP } & \multicolumn{4}{|c|}{ SIGTIERRAS } \\
\hline & 选 & $\begin{array}{l}\bar{z} \\
\bar{s} \\
\sum_{D}^{m}\end{array}$ & 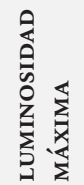 & 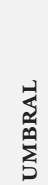 & 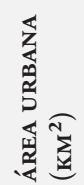 & 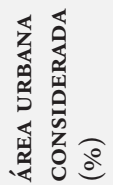 & 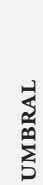 & $\begin{array}{l}\bar{J} \\
\bar{d} \\
\sum_{D}^{m}\end{array}$ & 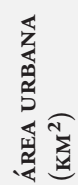 & 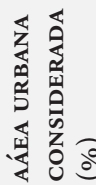 \\
\hline \multirow{10}{*}{ نू } & Babahoyo & \multirow{10}{*}{54} & 55 & 49 & 17,4 & 34 & \multirow{10}{*}{43} & - & - & - \\
\hline & Esmeraldas & & 60 & 43 & 31,6 & 72 & & - & - & - \\
\hline & Guayaquil & & 63 & 59 & 314,8 & 84 & & - & - & - \\
\hline & La Libertad & & 62 & 46 & 74,3 & 58 & & - & - & - \\
\hline & Machala & & 62 & 57 & 55,8 & 49 & & 54 & 56,4 & 50 \\
\hline & Manta & & 63 & 53 & 82,9 & 67 & & - & - & - \\
\hline & Portoviejo & & 61 & 46 & 51 & 56 & & - & - & - \\
\hline & Quevedo & & 60 & 40 & 40,9 & 61 & & - & - & - \\
\hline & Santa Rosa & & 62 & 57 & 58 & 47 & & - & - & - \\
\hline & \begin{tabular}{|l} 
Santo \\
Domingo
\end{tabular} & & 57 & 42 & 72,3 & 74 & & 42 & 70 & 58 \\
\hline \multirow{11}{*}{ 营 } & Ambato & \multirow{11}{*}{60} & 63 & 61 & 61,8 & 49 & \multirow{11}{*}{53} & 55 & 106 & 56 \\
\hline & Azogues & & 63 & 63 & 42 & 47 & & 52 & 133,4 & 67 \\
\hline & Cuenca & & 63 & 63 & 46,8 & 59 & & 55 & 163,9 & 66 \\
\hline & Guaranda & & 56 & 52 & 7,4 & 39 & & 45 & 14,6 & 31 \\
\hline & Ibarra & & 62 & 56 & 35,9 & 40 & & - & - & - \\
\hline & Latacunga & & 62 & 61 & 18 & 42 & & 41 & 57,3 & 53 \\
\hline & Loja & & 61 & 51 & 36,7 & 60 & & - & - & - \\
\hline & Otavalo & & 62 & 51 & 61,1 & 41 & & - & - & - \\
\hline & Quito & & 63 & 60 & 408,6 & 80 & & - & - & - \\
\hline & Riobamba & & 63 & 61 & 40,3 & 58 & & 60 & 45,8 & $56 \%$ \\
\hline & Tulcán & & 59 & 50 & 11,5 & 60 & & - & - & - \\
\hline \multirow{6}{*}{ 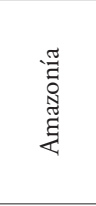 } & El Coca & \multirow{6}{*}{44} & 59 & 53 & 34,2 & 55 & \multirow{6}{*}{37} & 53 & 28,3 & $42 \%$ \\
\hline & Macas & & 43 & 33 & 11,4 & 57 & & 20 & 25,9 & $34 \%$ \\
\hline & Nueva Loja & & 59 & 52 & 22,7 & 60 & & 47 & 34,5 & $44 \%$ \\
\hline & Puyo & & 50 & 18 & 28,2 & 75 & & 31 & 32,5 & $34 \%$ \\
\hline & Tena & & 45 & 30 & 20,9 & 52 & & 30 & 25,6 & $38 \%$ \\
\hline & Zamora & & 29 & 25 & 0,9 & 74 & & 19 & 10,1 & $23 \%$ \\
\hline
\end{tabular}

TABLA 3 | Valores de máxima coincidencia entre áreas urbanas y área total por asentamientos en ámbitos de $25 \mathrm{~km}$ de radio

FUENTE: ELABORACIÓN PROPIA CON BASE EN DATOS DEL MAE E IMÁGENES DMSP-OLS

La tabla también permite constatar cómo, sin menoscabo de la posibilidad de establecer un umbral válido para el conjunto de los ámbitos considerados, el umbral de luminosidad urbana varía en cada uno de ellos. Eso se debe a que los asentamientos 
se encuentran en distintas zonas del territorio y a que cada uno posee características diversas. Así, los asentamientos con mayores extensiones producen una mayor intensidad lumínica y cubren más áreas de luz que los asentamientos menores. La luminosidad también depende de otros factores, como la cobertura de energía eléctrica, hábitos de consumo energético, calidad de infraestructura pública, densidad del asentamiento y estado del proceso de urbanización, entre otros.

Así, utilizando los datos del MAE, de manera general se mantiene la relación existente a nivel regional, donde los asentamientos de la Sierra presentan los umbrales más elevados, los que varían entre 50 y 63, seguidos de los de la Costa, que varían entre 40 y 59, y luego los de la Amazonía, que varían entre 18 y 53. Quito y Guayaquil, las ciudades más extensas del país, han alcanzado umbrales de luminosidad más o menos similares, 60 y 59. Los asentamientos más pequeños-Macas, Puyo y Zamora, emplazados en la región amazónica-, presentan los umbrales más bajos, 33,18 y 26 respectivamente. De esta forma, con los datos presentados en la tabla 3 se determinaría que el umbral de luminosidad urbana está vinculado con la extensión de suelo artificializado de cada asentamiento.

En la misma tabla se han identificado los niveles máximos de luminosidad que alcanzan las áreas urbanas de cada asentamiento, donde se observa que, dados los resultados obtenidos con la fuente del MAE, son varios los asentamientos que alcanzan el nivel máximo de luminosidad (63), lo que implica que en estas áreas urbanas se ha producido una saturación lumínica en las imágenes empleadas. La mayoría de las ciudades, donde se presenta este fenómeno superan los 300.000 habitantes. Por otro lado, las ciudades que concentran poblaciones inferiores a los 70.000 habitantes alcanzan un nivel máximo de luminosidad de 50 .

También, a fin de corroborar que el ámbito de $25 \mathrm{~km}$ es el más propicio para el análisis de procesos urbanos de los principales asentamientos, se realizó una comparación de los umbrales de luminosidad urbana correspondientes al ámbito de $50 \mathrm{~km}$ radio y al de $5 \mathrm{~km}$, aunque por cuestiones de extensión únicamente se mencionan los resultados. Es así como se ha corroborado que, si se disminuye del ámbito de $50 \mathrm{~km}$ al de $25 \mathrm{~km}$, se excluye suelo que corresponde al asentamiento próximo y se obtiene un umbral más propio del asentamiento considerado, tanto en los casos donde aumenta el umbral como en aquellos donde disminuye. En cambio, cuando se considera las variaciones entre los umbrales de $25 \mathrm{~km}$ a $5 \mathrm{~km}$, es lógico pensar que, al tomar únicamente las zonas centrales de los asentamientos, los umbrales sean superiores. En la mayoría de los casos esto es lo que sucede, obteniéndose umbrales con valores más elevados. En los pocos casos en los que disminuye el umbral de luminosidad, ello se debe a dos fenómenos. El primero es que el círculo de $25 \mathrm{~km}$ está superpuesto al núcleo del asentamiento vecino, lo que sucede con Sangolqui, que prácticamente está conurbado con Quito; Otavalo, que está próximo a Ibarra; Azogues, próximo a Cuenca; y Santa Rosa, próxima a Machala. Estas cuatro ciudades, de las 28 consideradas, disminuyen sus umbrales debido a que sus ciudades vecinas generan una mayor luminosidad. Al momento de considerar únicamente los $5 \mathrm{~km}$ de radio, se evita esta superposición y se obtienen valores del núcleo del asentamiento. El fenómeno opuesto se evidencia en la región norte de la Amazonía, donde las ciudades de El Coca y Nueva Loja poseen niveles 
de luminosidad inferiores en el ámbito de $5 \mathrm{~km}$, debido a que, al disminuir de 25 a $5 \mathrm{~km}$, se excluyen áreas con mayores niveles de luminosidad, pero que corresponden a infraestructuras antrópicas destinadas a complejos petroleros y de investigación. Estos usos son puntuales en el territorio; y por el tipo de actividades que se allí realizan, generan mayores niveles de luminosidad que los asentamientos que analizamos para el estudio de los procesos urbanos. Los valores obtenidos en zonas próximas a los asentamientos de El Coca y Nueva Loja corresponden a llamaradas de gas y usos vinculados a la extracción petrolera.

Finalmente, con el fin de incorporar datos de diferente índole que puedan ser contrastados con los ya obtenidos, y corroborar la relación que existe entre la luminosidad y los tejidos urbanos a partir de otras fuentes, se ha tomado como muestra el cantón Cuenca. Para este cruce de variables, se ha considerado la base de datos referentes a densidad poblacional elaborada por el GADMC. Esta fuente emplea un método distinto de la teledetección para la localización de usos residenciales, por lo que se incluyen áreas con usos urbanos que no están consideradas en las otras fuentes, por el nivel de detalle o la falta de continuidad con los centros urbanos mayores. Esta fuente corresponde al año 2010, por lo cual la imagen satelital nocturna con la que se ha realizado el cruce corresponde al mismo año. Se observó que la máxima coincidencia entre luminosidad y áreas urbanas se encuentra en el pixel 44, coincidencia que implica una relación entre área urbana iluminada con respecto al Área Total de $55,16 \%$ y abarca un $75,6 \%$ del área considerada con usos urbanos.

Los datos obtenidos reflejan que los niveles de luminosidad más bajos alcanzan porcentajes de suelo urbano menos urbanizados, mientras que los pixeles de mayor luminosidad (63) se encuentran completamente urbanizados. En la figura 2 se observa una relación constante entre nivel de luminosidad y nivel de urbanización, la cual alcanza un R2 de 0,98. Con ello se confirma de manera fehaciente la relación según la cual a mayor luminosidad, mayor nivel de urbanización.

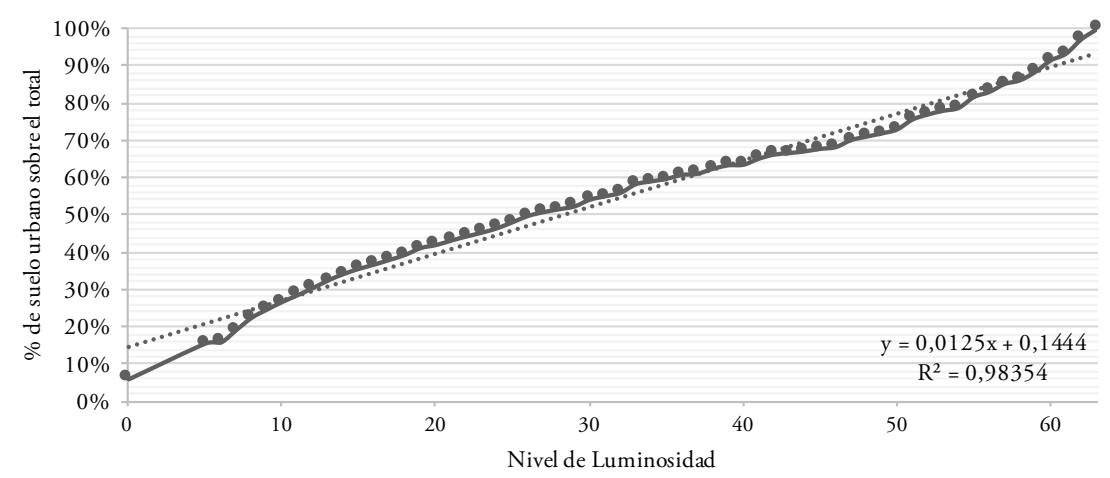

FIGURA 2 | Relación entre luminosidad y porcentaje de suelo urbano

FUENTE: ELABORACIÓN PROPIA CON BASE EN DATOS DE DMSP-OLS Y DENSIDADES DEL GADMC 
Una vez obtenidos los valores de los cruces de información con las fuentes consideradas, corresponde definir finalmente el umbral de luminosidad urbana que se utilizará de forma normativa para el estudio del conjunto de las áreas urbanas incluidas.

Analizando los niveles de máxima coincidencia obtenidos de la fuente MAE-MAGAP, se observó que estos no contemplan gran parte del suelo que se encuentra en proceso de consolidación. Por su parte, los umbrales derivados de Sigtierras, a pesar de la gran precisión de esta fuente -que incluye núcleos de población, áreas en proceso de urbanización, áreas periurbanas y demás infraestructura inmersa en estos tejidos urbanos-, no abarcan pequeńas zonas que claramente tienen usos urbanos. Finalmente, con la información del GADMC se obtiene un nivel de luminosidad más bajo, con lo que se abarca más suelo, sobre todo áreas con edificaciones de vivienda dispersa que corresponden a zonas con usos urbanos que no se encontraban identificadas en las anteriores fuentes de información. A la vista de estos datos, se ha adoptado el valor 44 como umbral de luminosidad urbana e indicador para determinar la evolución del proceso de urbanización en el periodo establecido (1992-2012). Como se ha visto, dicho valor se corresponde exactamente con el derivado de la información del GADMC y no se encuentra lejos de la media de los valores obtenidos para el conjunto de las áreas considerada a partir de las fuentes MAE-MAGAP (56) y de Sigtierras (50).

\section{Resultados. Evolución de los usos urbanos de suelo a partir de imágenes satelitales}

Establecido el umbral de luminosidad urbana más adecuado para el análisis del proceso de urbanización en Ecuador, puede procederse al estudio de la evolución temporal de la luminosidad. A ello se dedica el presente apartado. El análisis se llevará a cabo en tres etapas: en la primera se expondrá los valores medios de luminosidad nocturna en el radio de $25 \mathrm{~km}$ alrededor del centroide de las 28 áreas urbanas seleccionadas y su variación en el periodo 1992-2012. A continuación, se presenta un análisis de la superficie cubierta por el umbral de luminosidad urbano establecido en el apartado anterior, y su evolución durante estos últimos veinte años, así como la variación de las áreas con luminosidad urbana por periodos de cuatro años. Finalmente se presenta la relación de la luminosidad con variables que influyen en las dinámicas urbanas.

Para el desarrollo de este apartado, se ha excluido de los mapas y tablas los valores obtenidos para el asentamiento de Sangolqui, que en buena medida hacen referencia a la luz emitida por su ciudad vecina, Quito, dado que sus centroides se encuentran muy próximos.

\section{La evolución de los usos urbanos según la luminosidad nocturna}

Veamos, en primer lugar, cuál ha sido la evolución de la luminosidad media en el conjunto de las 28 áreas estudiadas. La luminosidad media corresponde a un valor obtenido mediante el cociente de la suma de los valores de luminosidad por cada unidad de superficie, dividido por la superficie total del ámbito considerado. 
La luminosidad media obtenida de manera general para todos los asentamientos pasó de 3,95 en el año 1992 a 11,04 en 2012; es decir, que se multiplicó por 2,8 veces su valor en dos décadas. Esta evolución nos muestra que en Ecuador la intensidad lumínica ha aumentado de manera considerable, a un ritmo muy superior al de la población, que se multiplicó por 1,5 según los censos del Instituto Nacional de Estadística y Censos (INEC) de 1990 y 2010, pasando de 9.648.189 a 14.483.499. El incremento relativo de la luminosidad también es muy superior al del PIB per cápita, que, a precios constantes en miles, según el Banco Mundial pasó de 3.782 en 1992 a 5.140 en 2012; es decir, un incremento de 35\%.

Establecida la luminosidad media para el conjunto de las áreas estudiadas, se ha determinado de manera específica la luminosidad media para cada asentamiento, con el objetivo de visualizar las diferencias territoriales existentes. De manera general, el aumento de la intensidad lumínica de la mayoría de asentamientos supera el 200\%. Así, el asentamiento con mayor luminosidad media para el año 2012 es Quito (32,8) superando ligeramente a Guayaquil (29,7). Estos partían ya en 1992 de unos niveles de luminosidad media elevados, por lo que sus incrementos, en términos relativos, no han sido tan acentuados como en otras áreas. Las ciudades amazónicas son las que mantienen los umbrales de luminosidad media más bajos, a excepción de Nueva Loja y El Coca que, como hemos dicho, constituyen casos especiales. En cuanto regiones naturales, tanto la Costa $(14,6)$ como la Sierra (15) mantienen niveles de luminosidad media similares para el ańo 2012, puesto que las dos regiones contienen los dos grandes centros de atracción de población, mientras que la Amazonía $(4,3)$ presenta la luminosidad media más baja. Estos niveles de luminosidad se han incrementado a más del doble desde 1992 en todas las regiones.

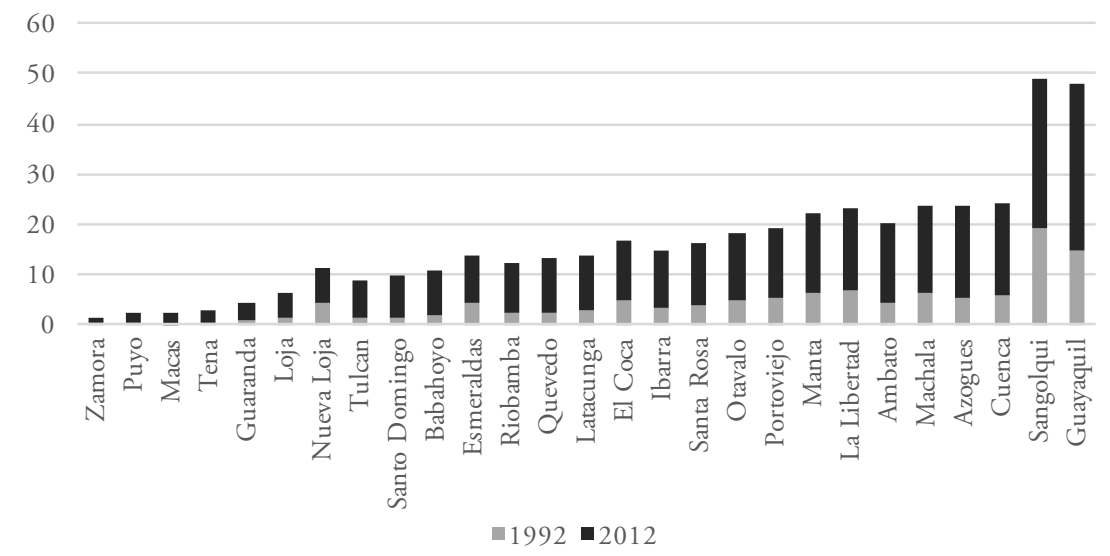

FIGURA 3 | Nivel de luminosidad media

FUENTE: ELABORACIÓN PROPIA CON BASE EN DATOS DMSP-OLS

Establecida la luminosidad media para el conjunto de áreas estudiadas y por asentamiento (figura 3), resulta ahora conveniente estudiar su evolución territorial a lo largo del periodo en consideración, para observar si el incremento de la luminosidad 
tiene lugar de forma más o menos continuada. Para ello es útil recurrir a un análisis por coronas, que permite determinar la continuidad y dispersión de las manchas de luz, para lo cual se han identificado cuatro coronas: la primera constituida por un radio de $5 \mathrm{~km}$, y el resto compuesto por la superficie de la circunferencia del radio que se indica, menos la superficie de las coronas inferiores. El resto de las coronas tiene un radio de 10,15 y $25 \mathrm{~km}$.

De manera general, con base en los resultados obtenidos y según se presenta en la figura 4, se evidencia como tendencia general la reducción gradual de los niveles de luminosidad media a medida que nos alejamos de la corona central.
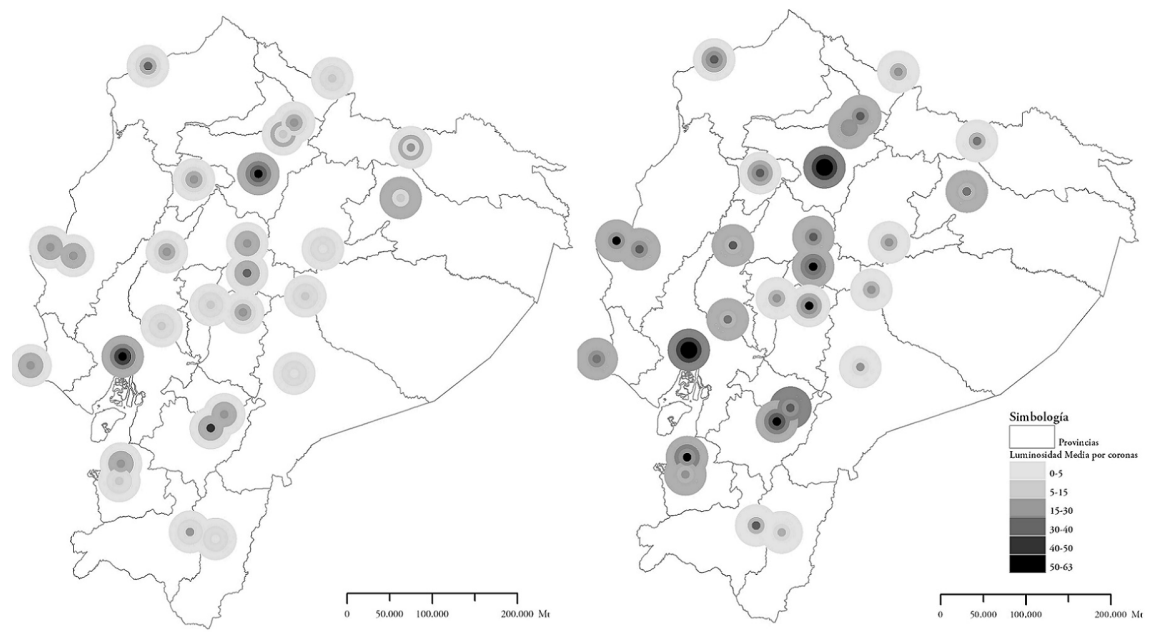

FIGURA 4 | Nivel de luminosidad media por coronas en 1992 y 2012

FUENTE: ELABORACIÓN PROPIA CON BASE EN DATOS DE DMSP-OLS

Al considerar los asentamientos más poblados, Quito y Guayaquil, se observa que alcanzan luminosidades medias superiores al resto de asentamientos tanto para el ańo 1992 como para 2012. Estas dos ciudades, al ser tan extensas, mantienen niveles de luminosidad elevados en todas las coronas, aunque también con reducciones graduales según nos alejamos del centro. En 2012, Quito alcanzó un nivel de luminosidad media en la primera corona de 61,7; y en la última corona, un nivel de 24,1. Guayaquil, en tanto, pasó de 62,2 en la primera corona a 17,2 en la última. Son estos valores los más elevados en comparación con el resto de asentamientos.

Por el lado contrario, al considerar las ciudades que abarcan menor volumen de población -Zamora, Macas, Puyo y Tena, todas localidades amazónicas- se observa que los niveles de luminosidad disminuyen de manera considerable, ya en la en la primera corona presentan niveles inferiores a 25 , mientras en la segunda están por debajo de 7 , con lo cual se evidencia que la mayor intensidad lumínica se concentra en un ámbito de $5 \mathrm{~km}$ de radio.

El análisis por coronas, además de mostrar la reducción gradual de la luz desde el centro de los asentamientos, permite constatar la existencia de procesos de urbanización consolidados discontinuos. Así, se visualiza que algunas ciudades que no 
siguen la tendencia general -la tercera y cuarta coronas de Babahoyo y Quevedo, por ejemplo- mantienen niveles de luminosidad superiores a las de la segunda corona. Igualmente, en el ámbito de El Coca y Nueva Loja, las coronas externas mantienen luminosidades medias elevadas por áreas artificializadas próximas al centro de los asentamientos, que son infraestructuras de carácter extractivo.

\section{Evolución de superficies de suelo con intensidad lumínica urbana}

Para analizar la evolución de las superficies vinculadas a los procesos urbanos en el territorio a través de la evolución de la luminosidad, se considerará el umbral de luminosidad urbana establecido anteriormente, el cual delimita las superficies que han alcanzado un nivel de luminosidad igual o superior a 44. Este nivel, según el método aplicado, es el que tiene una mayor correspondencia con los suelos de usos urbanos; ha sido verificado para el conjunto de los asentamientos estudiado dentro de los radios de $25 \mathrm{~km}$ de manera general y para cada uno de ellos.

Tomando en conjunto los asentamientos analizados, para el año 2012 existe una superficie de $2.982 \mathrm{~km}^{2}$ con niveles de luminosidad urbana, lo cual corresponde a un $6,01 \%$ del suelo considerado para este análisis. En términos comparativos, el estudio realizado por Nel.lo et al. (2017) para 48 ciudades espańolas detectaba niveles de luminosidad urbana en el 5,9\% del territorio comprendido dentro del radio de $50 \mathrm{~km}$ alrededor de los centroides urbanos. En un análisis por ciudades, se observa que las superficies con niveles de luminosidad urbana abarcan mayores extensiones en el ámbito de Quito $\left(792 \mathrm{~km}^{2}\right)$ y Guayaquil $\left(579 \mathrm{~km}^{2}\right)$. Para el resto de ciudades, con poblaciones que, dentro de sus ámbitos de estudio, abarcan entre 600.000 y 200.000 habitantes, las superficies con intensidades de luminosidad urbana varían entre $250 \mathrm{~km}^{2}$ y $40 \mathrm{~km}^{2}$. Los asentamientos menores con menos de 100.000 habitantes presentan superficies iluminadas inferiores a los $40 \mathrm{~km}^{2}$. Se ha determinado que existe una relación entre superficie con luminosidad urbana y población del ámbito de R2=0,92, lo cual es obviamente un valor significativo, con lo que se puede concluir que la superficie iluminada está vinculada de manera directa con la población que abarca el área urbana.

Una vez obtenidos los datos relativos a las superficies del conjunto de asentamientos y por asentamientos, se ha analizado la localización de estas áreas por coronas. En valores generales del conjunto de asentamientos, al examinar la relación entre superficie con luminosidad urbana y superficie de coronas, resulta evidente que las superficies disminuyen desde la primera corona hasta la última. En el conjunto de los asentamientos, esta relación disminuye del 53\% en la primera corona, a $14 \%$ en la corona de $10 \mathrm{~km}, 5 \%$ en la de $15 \mathrm{~km}$ y $1 \%$ en la última corona, la de $25 \mathrm{~km}$. Es decir, al igual que la luminosidad media ponderada, la superficie se concentra en la primera corona y disminuye de manera gradual hasta la última corona.

Definidas las superficies con luminosidad urbana para el año 2012 por asentamiento, se ha analizado la evolución de la luminosidad desde el año 1992, lo cual ofrece una perspectiva temporal adecuada para visualizar el crecimiento de las ciudades y las posibles desigualdades territoriales que se han generado entre ellas (los valores por ciudades se presentan en la figura 5). Desde 1992, se observa un incremento sustancial de las áreas con niveles de luminosidad urbana, la cual 
se ha multiplicado prácticamente por cuatro hasta el año 2012. En 1992 existían $785,4 \mathrm{~km}^{2}$ con un valor de luminosidad superior o igual a 44 (umbral definido como de luminosidad urbana para Ecuador), el cual se ha incrementado hasta 2012, cuando alcanza una extensión de $2.982 \mathrm{~km}^{2}$; es decir, que la superficie con niveles de luminosidad urbana se ha multiplicado por 3,8.
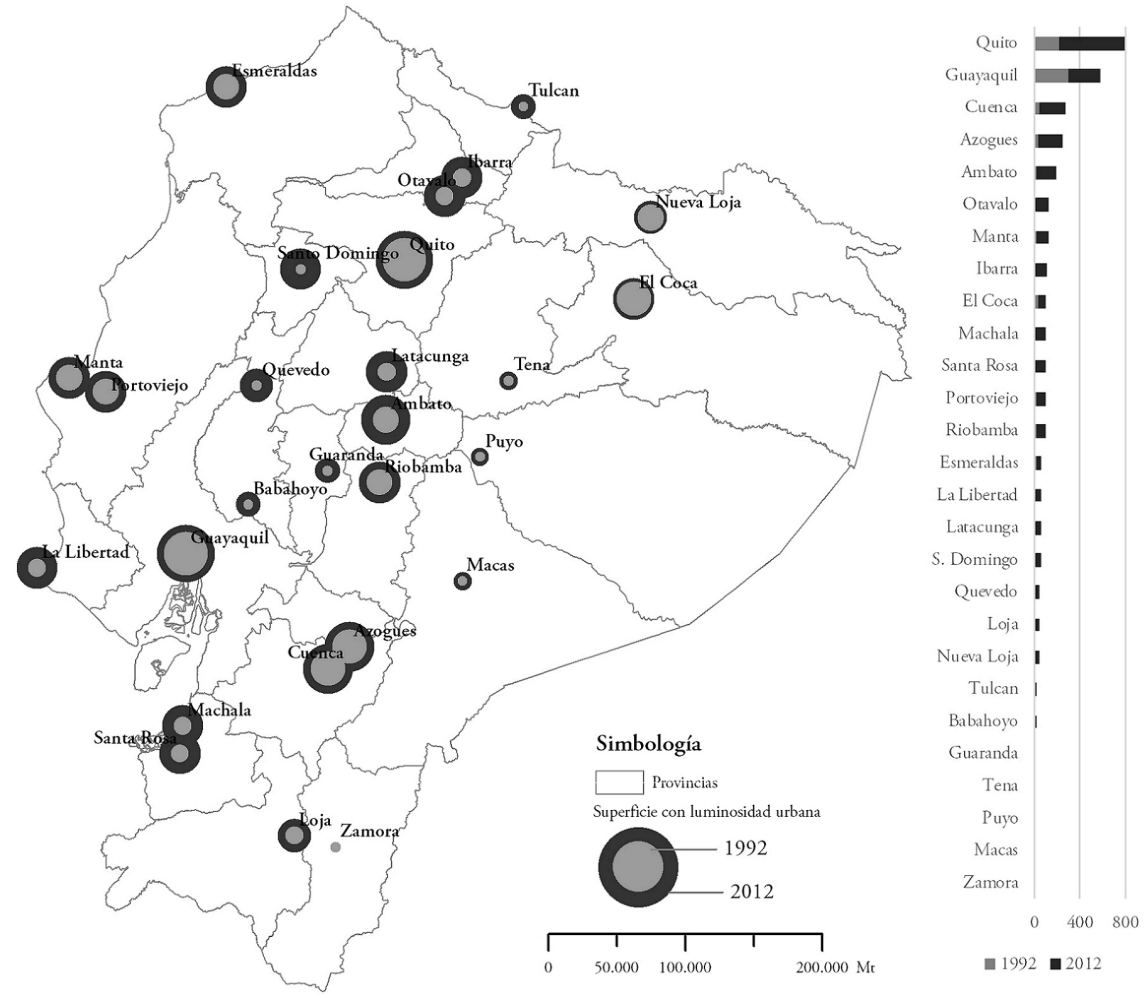

FIGURA 5 | Evolución de superficie de suelo con niveles de luminosidad urbana entre 1992-2012

FUENTE: ELABORACIÓN PROPIA CON BASE EN DATOS DE DMSP-OLS

En la figura 5 se ilustra que Guayaquil y Quito, en valores absolutos, registran los mayores incrementos de superficie, con 276 y $568 \mathrm{~km}^{2}$ respectivamente. Ello aunque, de manera general, se ha observado que las ciudades de escala intermedias son las que porcentualmente han aumentado más su superficie con luminosidad urbana en los veinte años que se analizan. Es el caso de Machala, donde se multiplicó por 16, pasando de una superficie de 6 km² en 1992 a 97 km$^{2}$ en 2012.

También se evidencia que ciudades que en 1992 no contaban con superficie con luminosidad urbana, en el año 2012 han elevado sus respectivos niveles de luminosidad hasta alcanzar este umbral. Es el caso de la ciudad de Santo Domingo, que en 1992 no alcanzaba los niveles de luminosidad urbana, y que actualmente es una de las ciudades más pobladas y extensas del país, lo cual da cuenta de las transformaciones urbanas intensas que ha conocido a lo largo de estos ańos. 


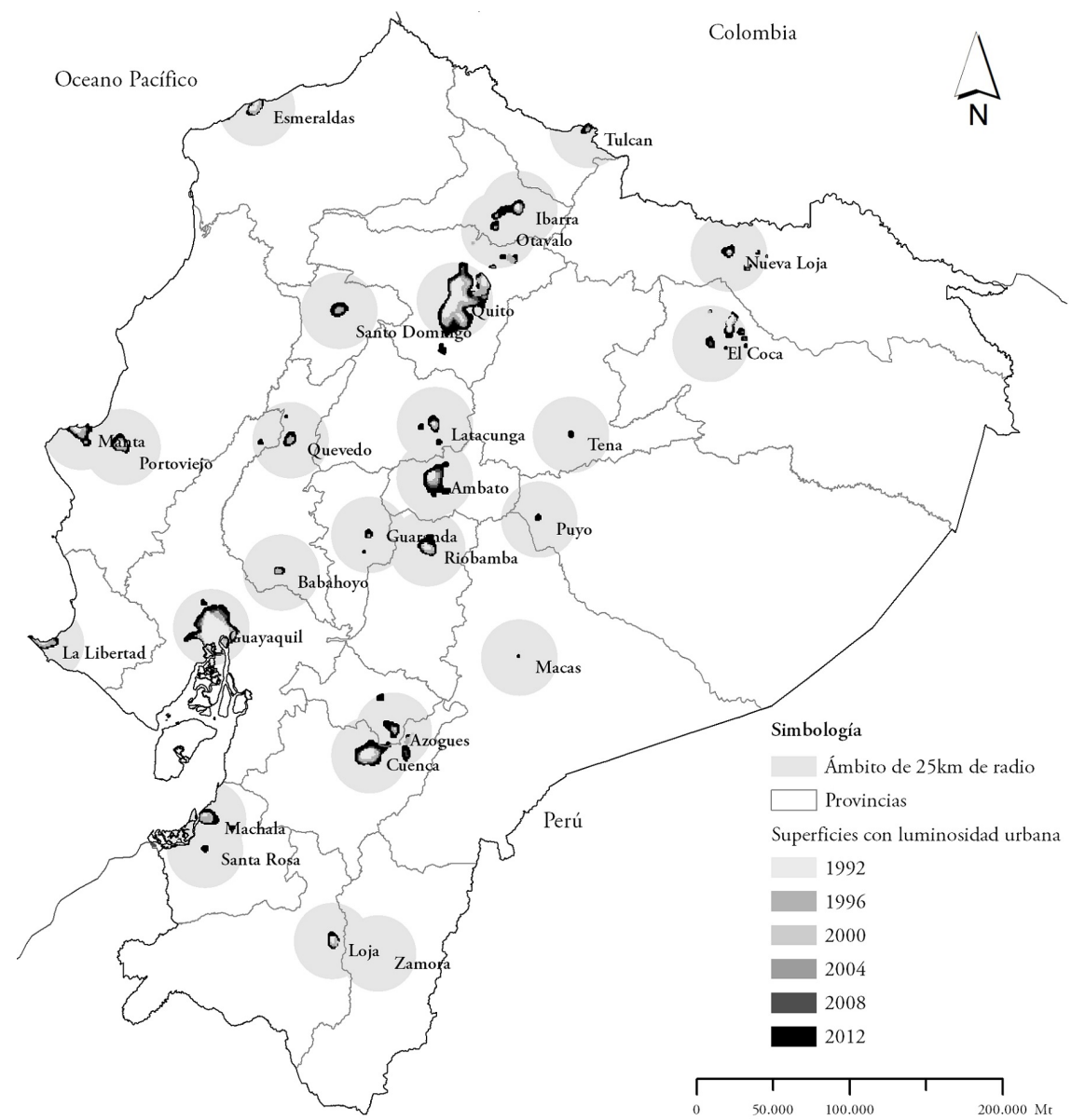

FIgURa 6 | Evolución de Superficie en $\mathrm{km}^{2}$ por periodos de cuatro años por asentamientos

FUENTE: ELABORACIÓN PROPIA, CON BASE EN DATOS DMSP-OLS

Analizada la evolución general de la superficie durante el periodo de veinte años establecido para este estudio (figura 6), se ha examinado la variación experimentada por las superficies con luminosidad urbana a lo largo de esos años, considerando periodos de cuatro ańos. Este intervalo fue definido por ser adecuado para visibilizar los posibles procesos evolutivos territoriales nacionales, mientras que los intervalos estables de tiempo nos permiten comparar la evolución de los procesos urbanos en distintos momentos. En este sentido, se debe mencionar que el periodo con menor variación es 1996-2000, ya que, según el análisis realizado para este lapso, varias ciudades redujeron su intensidad lumínica, generando así una disminución de la superficie con luminosidad urbana. Tal es el caso de las ciudades de Loja, Esmeraldas, Santa Rosa, Machala y Azogues. Tomando el conjunto de los 28 asentamientos, se obtuvo una merma de $98 \mathrm{~km}^{2}$ de superficie con luminosidad urbana, 
la cual pudo haber sido ocasionada por diversos factores: la calibración del satélite del año 2010, variaciones demográficas, cobertura o funcionamiento del servicio eléctrico o la coyuntura económica de los asentamientos, como han descrito otros estudios que han vinculado la evolución de la luminosidad con la estimación del producto interno bruto y nivel de desarrollo de los países (Shi et al., 2014). Es así que esta disminución de superficie puede estar vinculada con un fenómeno económico de gran envergadura que tuvo lugar en el país en 1999: la dolarización. Ese año se produjo una disminución de la tasa de variación anual del PIB, que llegó a un valor negativo de 6,3\%, según el Banco Central del Ecuador (con valores constantes al año 2000).

Por su parte, se ha observado que el periodo con más incremento de superficie es el último, 2008-2012. La superficie bruta con luminosidad urbana aumentó en este periodo en $1.324 \mathrm{~km}^{2}$, es decir, que prácticamente se duplicó la superficie con luminosidad urbana, ya que en el periodo anterior, 2004-2008, se obtuvo una extensión de $1.658 \mathrm{~km}^{2}$.

Relación entre superficies con niveles de luminosidad urbana y variables que influyen en las dinámicas urbanas

$\mathrm{Al}$ considerar los incrementos de las áreas con luminosidad urbana y los de las áreas delimitadas como urbanas por el MAE, se ha constatado que existe una correlación de R2 $=0,78$, aunque los incrementos de las superficies con luminosidad urbana, en números absolutos, son superiores. De acuerdo con los resultados obtenidos, la superficie de suelo con cobertura urbana, en cifras del MAE, pasó de $568,5 \mathrm{~km}^{2}$ en 1990 a $1.550,1 \mathrm{~km}^{2}$ en 2013; es decir, que se expandió por 2,7 veces. Por su parte, las áreas con luminosidad urbana prácticamente se cuadruplicaron. En definitiva, las coberturas urbanas se incrementaron en $981,5 \mathrm{~km}^{2}$, mientras que la luz se incrementó en $2.196,6 \mathrm{~km}^{2}$; esto es, 2,23 veces más que las áreas con coberturas urbanas. Se puede afirmar así que en Ecuador en los veinte años estudiados, las superficies con luminosidad urbana han crecido más del doble que las áreas delimitadas como urbanas.

Además, es importante destacar que la evolución de las superficies con luminosidad urbana calculada en esta investigación mantiene un coeficiente de correlación de 0,7 con la evolución de la población y de 0,6 con el PIB durante el periodo analizado. Aunque estas variables crecen a ritmos distintos, la población entre 1992 y 2012 se incrementó en un 50\%, el PIB per cápita registró un aumento de un 35\%, mientras que la luminosidad media creció en $280 \%$ y la superficie con luminosidad urbana registra un incremento de $379 \%$. Estos valores nos ayudan a distinguir el modelo del proceso de urbanización, ya que, tal como se ha explicado (Nel.lo et al., 2017), los asentamientos compactos generan menor halo de luz hacia su entorno iluminando menos superficie periférica, mientras que los asentamientos dispersos generan una mayor difuminación de luz, iluminando así superficies más extensas. Por otra parte, al considerar el incremento de la superficie con luminosidad urbana y la población, se observa que el modelo expansivo de baja densidad es cada vez más acentuado (figura 7). 


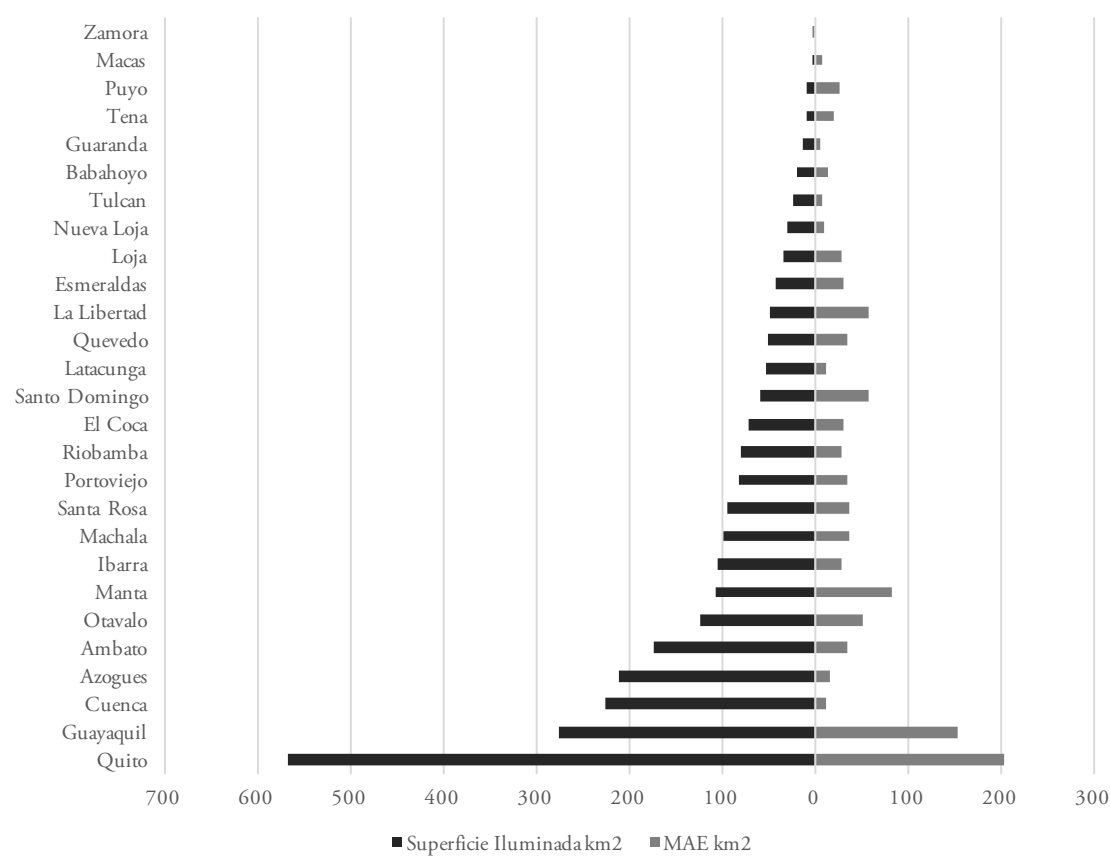

FIGURA 7 | Incremento de superficies con luminosidad urbana y suelo urbano FUENTE: ELABORACIÓN PROPIA CON BASE EN DATOS DE DMSP-OLS Y MAPA DE COBERTURAS MAE I 990 Y 2013

\section{Conclusiones}

El artículo ha mostrado la relación existente entre el proceso de urbanización y la evolución de la luminosidad artificial nocturna. Además, ha permitido corroborar la utilidad de la metodología empleada a la hora de medir la evolución de las dinámicas territoriales. Las conclusiones principales derivadas del estudio son las siguientes:

a. En primer lugar, se ha establecido la factibilidad de definir un umbral de luminosidad urbana para el conjunto de las principales ciudades de Ecuador. El contraste entre la imagen satelital nocturna y las diversas fuentes relativas a la cobertura de los suelos artificializado ha permitido establecer que el umbral más adecuado a estos efectos es el valor 44 del rango 0-63 de las imágenes satelitales del DMsp.

b. Establecido el umbral, se ha procedido a definir la evolución de la luminosidad media ponderada en un radio de $25 \mathrm{~km}$ alrededor de los centroides de las 28 principales áreas urbanas ecuatorianas. De acuerdo con los resultados obtenidos, esta se multiplicó entre 1992 y 2012 por 2,8 veces, pasando de un valor medio de 3,95 a 11,04. 
c. En tercer lugar, se ha podido determinar que en el ámbito descrito de $25 \mathrm{~km}$ alrededor de los centros urbanos, la superficie con nivel de luminosidad urbana ha pasado de $785 \mathrm{~km}^{2}$ en 1992 a $2.982 \mathrm{~km}^{2}$. Se puede afirmar así que mientras la intensidad de la luminosa media se ha triplicado, la superficie con luminosidad urbana se ha cuadriplicado: el suelo con luminosidad urbana se incrementa, pues, a un ritmo más acelerado que la intensidad lumínica.

d. La comparación de la luminosidad urbana con las superficies artificializadas permite cuantificar que mientras en el ańo 2012 la superficie cubierta por luminosidad urbana alcanzaba los $29.82 \mathrm{~km}^{2}$, el suelo artificializado comprendía $1.550 \mathrm{~km}^{2}$, según datos MAE. Los datos procedentes de la fuente Sigtierras confirmaban, asimismo, la extensión muy superior de la luminosidad respecto del suelo delimitado como urbano, aun considerando un ámbito más reducido.

e. Además, se ha podido constatar que, en los veinte años estudiados, la superficie de las áreas con luminosidad urbana aumentó 2,23 veces más que las áreas con coberturas urbanas.

f. Finalmente, los resultados aquí obtenidos pueden ser considerados como un indicador para cuantificar la evolución de los procesos urbanos a escala nacional. Los datos respectivos no han dado lugar hasta el momento a un estudio general, aun cuando han sido abordados por la literatura y los órganos administrativos locales. En términos generales, estas aproximaciones consideran que la expansión de los usos urbanos constituye una materia de gran envergadura que debe ser atendida de manera perentoria.

En conjunto, los datos relativos a la luminosidad a partir de la imagen satelital nocturna permiten constatar el vigor del proceso urbanizador en Ecuador, la tendencia a la expansión de las áreas urbana y la dispersión de la urbanización, la emergencia de nuevas centralidades y la extensión de los usos urbano sobre el territorio mucho más allá de las áreas de suelo delimitadas como urbanas.

\section{Referencias bibliográficas}

Benabent, M. \& Vivanco, L. (2017). El ordenamiento territorial y el urbanismo en el Ecuador y su articulación competencial. Ciudady Territorio, Estudios Territoriales, 49(194), 713726. https://apps.fomento.gob.es/CVP/handlers/pdfhandler.ashx?idpub=BP1022

Bharti, N., Tatem, A. J., Ferrari, M. J., Grais, R. F., Djibo, A., \& Grenfell, B. T. (2011). Explaining seasonal fluctuations of measles in Niger using nighttime lights imagery. Science, 334(6061), 1424-1427. http://doi.org/10.1126/science.1210554

Carrión, F. (1994). Las ciudades intermedias en el contexto de la urbanización ecuatoriana: un intento de interpretación. Revista Interamericana de Planificación, 18(71), 129-147. https://works.bepress.com/fernando_carrion/59/ 
Davis, M. (2007 [2006]). Planeta de ciudades miseria. Trad. J. M. Amoroto. Madrid: Akal. https://redpaemigra.weebly.com/uploads/4/9/3/9/49391489/planeta_de_ciudades_ miseria_-_davis_mike.pdf

Elvidge, C. D., Baugh, K. E., Anderson, S. J., Sutton, P. C., \& Ghosh, T. (2012). The Night Light Development Index (NLDI): a spatially explicit measure of human development from satellite data. Social Geography, 7(1), 23-35. https://doi.org/10.5194/sg-7-232012.

Elvidge, C. D., Baugh, K. E., Sutton, P. C., Bhaduri, B., Tuttle, B. T., Ghosh, T., Ziskin, D., \& Erwin, E. H. (2011). Who's in the dark - Satellite based estimates of electrification rates. En X. Yang (ed.), Urban Remote Sensing (pp. 211-224). Hoboken, NJ: John Wiley \& Sons. https://doi.org/10.1002/9780470979563.ch15.

Indovina, F. (coord.) (2007). La ciudad de baja densidad: lógicas, gestión y contención. Colección Estudios. Serie Territorio 1. Barcelona: Diputació Provincial de Barcelona. https:// www1.diba.cat/uliep/pdf/38454.pdf

Kyba, C. C. M., Kuester, T., Sánchez de Miguel, A., Baugh, K., Jechow, A., Hölker, F., \& Guanter, L. (2017). Artificially lit surface of Earth at night increasing in radiance and extent. Science Advances, 3(11), e1701528. https://doi.org/10.1126/sciadv.1701528

Levin, N. \& Duke, Y. (2012). High spatial resolution night-time light images for demographic and socio-economic studies. Remote Sensing of Environment, 119, 1-10. https://doi. org/10.1016/j.rse.2011.12.005

Li, X., Zhang, R., Huang, C., \& Li, D. (2015). Detecting 2014 Northern Iraq Insurgency using night-time light imagery. International Journal of Remote Sensing, 36(3), 34463458. https://doi.org/10.1080/01431161.2015.1059968

Liang, H., Tanikawa, H., Matsuno, Y., \& Dong, L. (2014). Modeling in-use steel stock in China's buildings and civil engineering infrastructure using time-series of DMSP/ oLs nighttime lights. Remote Sensing, 6(6), 4780-4800. https://doi.org/10.3390/ rs6064780

López, J. (2017). Mobilitat quotidiana, consum de carburants i forma urbana a la regió metropolitana de Barcelona. Documentes d'Anàlisi Geogräfica, 63(2), 447-471. http:// dx.doi.org/10.5565/rev/dag.347

Ma, T., Zhou, C., Pei, T., Haynie, S., \& Fan, J. (2012). Quantitative estimation of urbanization dynamics using time series of DMSP/OLs nighttime light data: A comparative case study from China's cities. Remote Sensing of Environment, 124, 99-107. http://doi. org/10.1016/j.rse.2012.04.018

Muñoz, F. (2007). La producción residencial de baja densidad en la provincia de Barcelona (1985-2001). En F. Indovina (coord.), La ciudad de baja densidad: lógicas, gestión y contención (pp. 51-84). Barcelona: Diputació Provincial de Barcelona.

Nel.lo, O. (1998). Los confines de la ciudad sin confines. Estructura urbana y límites administrativos en la ciudad difusa. En F. J. Monclús (ed.), La ciudad dispersa (pp. 3557). Barcelona: Centre de Cultura Contemporània de Barcelona.

Nel.lo, O. (dir.), López, J., Martín, J., \& Checa, J. (2017). La luz de la ciudad. El proceso de urbanización en España a partir de las imágenes nocturnas de la Tierra. Barcelona: Grup d'Estudis sobre Energia, Territori i Societat. Departament de Geografia, Universitat Autònoma de Barcelona. https://bit.ly/2RQUwbA 
Prada-Trigo, J. (2016). Desarrollo territorial en tres ciudades medias ecuatorianas: efecto de las estrategias locales en la aplicación del Plan Nacional del Buen Vivir y el cambio en la Matriz productiva. Cuadernos Geográficos, 55(1), 125-148. http://www.redalyc.org/ articulo.oa?id=17146265005

Roberts, B. (2015). Gestionando sistemas de ciudades secundarias. Washington, DC: Cities Alliance / Banco Interamericano de Desarrollo. https://bit.ly/2YyI2HO

Shi, K., Yu, B., Huang, Y., Hu, Y., Yin, B., Chen, Z., \& Wu, J. (2014). Evaluating the ability of NPP-VIIRs nighttime light data to estimate the gross domestic product and the electric power consumption of China at multiple scales: A comparison with DMSP-OLs data. Remote Sensing, 6(2), 1705-1724. https://doi.org/10.3390/rs6021705

Soja, E. W. (2008). Postmetrópolis. Estudios críticos sobre las ciudades y las regiones. V. Hendel \& M. Cifuentes (trads.). Madrid: Traficantes de Sueńos. https://doi.org/10.1017/ CBO9781107415324.004

Zhao, N., Currit, N., \& Samson, E. (2011). Net primary production and gross domestic product in China derived from satellite imagery. Ecological Economics, 70(5), 921-928. https://doi.org/10.1016/j.ecolecon.2010.12.023 